Check for updates

Cite this: Phys. Chem. Chem. Phys., 2018, 20, 4793

Received 9th November 2017, Accepted 17th January 2018

DOI: $10.1039 / c 7 c p 07570 g$

rsc.li/pccp

\section{Reactivity of hydropersulfides toward the hydroxyl radical unraveled: disulfide bond cleavage, hydrogen atom transfer, and proton-coupled electron transfert}

\author{
Josep M. Anglada, (D) *a Ramon Crehuet, (D) a Sarju Adhikari, (D) b \\ Joseph S. Francisco (iD ${ }^{c}$ and Yu Xia (D) ${ }^{\text {bd }}$
}

\begin{abstract}
Hydropersulfides (RSSH) are highly reactive as nucleophiles and hydrogen atom transfer reagents. These chemical properties are believed to be key for them to act as antioxidants in cells. The reaction involving the radical species and the disulfide bond (S-S) in RSSH, a known redox-active group, however, has been scarcely studied, resulting in an incomplete understanding of the chemical nature of RSSH. We have performed a high-level theoretical investigation on the reactions of the hydroxyl radical $(\bullet \mathrm{OH})$ toward a set of RSSH $\left(\mathrm{R}=-\mathrm{H},-\mathrm{CH}_{3},-\mathrm{NH}_{2},-\mathrm{C}(\mathrm{O}) \mathrm{OH},-\mathrm{CN}\right.$, and $\left.-\mathrm{NO}_{2}\right)$. The results show that $\mathrm{S}-\mathrm{S}$ cleavage and $\mathrm{H}$-atom abstraction are the two competing channels. The electron inductive effect of $\mathrm{R}$ induces selective $\bullet \mathrm{OH}$ substitution at one sulfur atom upon $\mathrm{S}-\mathrm{S}$ cleavage, forming $\mathrm{RSOH}$ and $\bullet \mathrm{SH}$ for the electron donating groups (EDGs), whereas producing $\mathrm{HSOH}$ and $\bullet \mathrm{SR}$ for the electron withdrawing groups (EWGs). The $\mathrm{H}$-Atom abstraction by ${ }^{\bullet} \mathrm{OH}$ follows a classical hydrogen atom transfer (hat) mechanism, producing RSS ${ }^{\bullet}$ and $\mathrm{H}_{2} \mathrm{O}$. Surprisingly, a proton-coupled electron transfer (pcet) process also occurs for R being an EDG. Although for RSSH having EWGs hat is the leading channel, S-S cleavage can be competitive or even dominant for the EDGs. The overall reactivity of $\mathrm{RSSH}$ toward $\bullet \mathrm{OH}$ attack is greatly enhanced with the presence of an EDG, with $\mathrm{CH}_{3} \mathrm{SSH}$ being the most reactive species found in this study (overall rate constant: $4.55 \times 10^{12} \mathrm{M}^{-1} \mathrm{~s}^{-1}$ ). Our results highlight the complexity in RSSH reaction chemistry, the extent of which is closely modulated by the inductive effect of the substituents in the case of the oxidation by hydroxyl radicals.
\end{abstract}

\section{Introduction}

Disulfides are important species in chemistry and in biology. Disulfide bridges play an important role in protein folding, in regulatory proteins, in the synthesis of peptides and antibiotics, in hair keratins, in synthetic chemistry, in vulcanization processes, and in atmospheric chemistry. ${ }^{1-7}$ Disulfides undergo substitution by nucleophiles and radicals. Krenske and co-workers ${ }^{8}$ have investigated the reaction of the methyl radical with several disulfides, pointing out the existence of two different reaction

\footnotetext{
${ }^{a}$ Institute of Advanced Chemistry of Catalonia IQAC-CSIC, Barcelona, Spain. E-mail: anglada@iqac.csic.es

${ }^{b}$ Department of Chemistry, Purdue University, West Lafayette, Indiana, USA

${ }^{c}$ Department of Chemistry, University of Nebraska-Lincoln, NE, USA

${ }^{d}$ Department of Chemistry, Tsinghua University, Beijing, China

$\dagger$ Electronic supplementary information (ESI) available: The supplementary information contains a figure with the main geometrical parameters of the pre-reactive complexes of the $\mathrm{HSSH}+\mathrm{OH}$ reaction, and tables including the relative energies of all reactions investigated, the absolute energies, the main topological parameters of selected transition states, the rate constants for all the elementary reactions investigated and the Cartesian coordinates of all stationary points considered. See DOI: 10.1039/c7cp07570g
}

mechanisms for the interaction of the radical with the disulfide molecules. These two reaction mechanisms involve a backside and a frontside attack of the radical on each sulfur atom. Krenske concluded that the backside attack is the preferred process and the same conclusions were also found in previous investigations on the radical substitution at the sulfur of several disulfides as well as in the nucleophilic substitution reactions. ${ }^{9-12}$

An important class of disulfides are hydropersulfides (RSSH), which have been measured with significant levels in mammalian cells, tissues, and plasma. These RSSH (e.g., cysteine hydropersulfide and glutathione hydropersulfide) are found to be superior nucleophiles, playing an important role in regulating electrophilic cell signaling and in redox modulatory effects. ${ }^{13-18}$ Everett and Wardman have studied the antioxidant ability of perthiols, ${ }^{19}$ and in a very recent work, Bianco and co-workers have demonstrated that the RSSH species are easily oxidized producing the RSS perthiyl radicals. ${ }^{20}$ Chauvin and co-workers ${ }^{21}$ have also pointed out that RSSH are excellent hydrogen transfer agents towards alkyl, alkoxyl, peroxyl, and thiyl radicals, and concluded that these species have an important radical-trapping antioxidant activity and could act as therapeutic agents for diseases involved in 
lipid peroxidation. The high reactivity of RSSH in redox reactions so far has only being explained from its nucleophilicity (in the form of perthiolate, $\mathrm{RSS}^{-}$) and $\mathrm{H}$-atom abstraction capability (in the form of the perthiyl radical, $\mathrm{RSS}^{\bullet}$ ). Reactions involving the disulfide bond, the other obvious redox reactive functional group within RSSH, however, have been historically overlooked, leading to an incomplete mechanistic picture when considering the antioxidant reactivity of RSSH toward oxidative radicals.

In this work, we aim to provide a comprehensive understanding of the elementary steps regarding the reactions of $\mathrm{RSSH}$ and the hydroxyl radical $\left({ }^{\bullet} \mathrm{OH}\right)$, a highly reactive oxygen species produced endogenously in aerobic cells. Modification of biomolecules caused by increased levels of hydroxyl radical often leads to irreversible cell damage when the cells are under oxidative stress. $^{22-24}$ Given the newly discovered role of RSSH in cell redox signaling, ${ }^{13}$ it is of importance to investigate how these compounds react with hydroxyl radicals. Herein, we have modeled the reactions of a series of $\mathrm{RSSH}$, with $\mathrm{R}$ being $\mathrm{H}$, the electron donating group (EDG, $-\mathrm{CH}_{3}$ and $-\mathrm{NH}_{2}$ ), and the electron withdrawing group (EWG, $-\mathrm{COOH},-\mathrm{CN}$, and $-\mathrm{NO}_{2}$ ). These model compounds provide a unique opportunity to probe the reaction mechanisms and kinetics via modulating the inductive effects of the substituents. In particular, we have considered the attack of the hydroxyl radical on each of the two sulfur atoms (reaction (1) and (2)) and the abstraction of the hydrogen atom by the hydroxyl radical (reaction (3)).

$$
\begin{gathered}
\mathrm{RSSH}+{ }^{\bullet} \mathrm{OH} \rightarrow \mathrm{HSOH}+{ }^{\bullet} \mathrm{SR} \\
\mathrm{RSSH}+{ }^{\bullet} \mathrm{OH} \rightarrow \mathrm{RSOH}+{ }^{\bullet} \mathrm{SH} \\
\mathrm{RSSH}+{ }^{\bullet} \mathrm{OH} \rightarrow{ }^{\bullet} \mathrm{SSR}+\mathrm{H}_{2} \mathrm{O}
\end{gathered}
$$

The products of reactions (1) and (2) are thioperoxide $(\mathrm{HSOH})$ and sulfenic acid (RSOH) along with the thiyl radicals $\left(\mathrm{RS}^{\bullet}\right.$ and $\left.\mathrm{HS}^{\bullet}\right)$. Given the well-known role of sulfenic acids in redox signaling, ${ }^{25-28}$ we have further investigated the reactions between these species (reactions (4)-(8)). Please note that reactions (4) and (7) are the reverse processes of reactions (1) and (2), but reactions (5), (6) and (8) correspond to hydrogen transfer processes from thioperoxide $(\mathrm{HSOH})$ and sulfenic acid $(\mathrm{RSOH})$ to the thiyl radicals $\left(\mathrm{RS}^{\bullet}\right.$ and $\left.\mathrm{HS}^{\bullet}\right)$. This study also allows us to compare the hydrogen transfer ability of these thioperoxides with the RSSH described by reaction (3).

$$
\begin{aligned}
& \mathrm{HSOH}+\mathrm{RS}^{\bullet} \rightarrow \mathrm{RSSH}+{ }^{\bullet} \mathrm{OH} \\
& \mathrm{HSOH}+\mathrm{RS}^{\bullet} \rightarrow \mathrm{HSO}^{\bullet}+\mathrm{HSR} \\
& \mathrm{HSOH}+\mathrm{RS}^{\bullet} \rightarrow \mathrm{HOS}^{\bullet}+\mathrm{HSR} \\
& \mathrm{RSOH}+\mathrm{HS}^{\bullet} \rightarrow \mathrm{RSSH}+{ }^{\bullet} \mathrm{OH} \\
& \mathrm{RSOH}+\mathrm{HS}^{\bullet} \rightarrow \mathrm{RSO}^{\bullet}+\mathrm{SH}_{2}
\end{aligned}
$$

\section{Computational methods}

We have employed different theoretical methods for the study on the reactions investigated in this work. In a first step, we have carried out density functional theory calculations employing the BH\&HLYP functional, ${ }^{29}$ with the $6-311+\mathrm{G}(2 \mathrm{df}, 2 \mathrm{p})$ basis set $^{30,31}$ to optimize and characterize the stationary points (minima and transition states) along the potential energy surfaces. The zero-point energies (ZPE) and the enthalpic and entropic corrections have been obtained from the frequency calculations of each stationary point. At this level of theory, we have also carried out intrinsic reaction coordinate (IRC) calculations, ${ }^{32-34}$ in order to make sure that each transition state correlates with the desired reactants and products. In addition, at each stationary point, we have performed single point energy calculations at the $\operatorname{CCSD}(\mathrm{T})$ level of theory ${ }^{35-38}$ with the aug-cc-pV(T+d)Z basis set, ${ }^{39-41}$ in order to obtain more reliable relative energies.

In a second step, we have re-optimized all stationary points at the QCISD ${ }^{42}$ level of theory using the $6-311+\mathrm{G}(2 \mathrm{df}, 2 \mathrm{p})$ basis set and, at each optimized geometry, we have also performed single point energy calculations at the $\operatorname{CCSD}(\mathrm{T})$ level of theory with the aug-cc-pV(T+d)Z basis set. The relative energies computed at $\operatorname{CCSD}(\mathrm{T}) / / \mathrm{BH} \& H L Y P$ and $\operatorname{CCSD}(\mathrm{T}) / / \mathrm{QCISD}$ compare very well with the RMS values of the difference between the relative energies calculated with both approaches ranging between 0.37 and $0.62 \mathrm{kcal} \mathrm{mol}^{-1}$ (see Table S7 of the ESI $\dagger$ ), indicating that the DFT approach provides accurate optimized geometries for these kinds of reactions. The energetic values discussed along this work correspond to those obtained at this level of theory but considering the ZPE and the enthalpic and entropic correction computed at BH\&HLYP level. All these calculations have been carried out with the Gaussian 09 program package. $^{43}$

The bonding features have been analyzed by using the topological theory of Atoms in Molecules (AIM) of Bader, ${ }^{44}$ using the AIMPAC program package, ${ }^{45}$ and natural bond orbital analysis (NBO) by Weinhold and co-workers. ${ }^{46}$ The Molden program $^{47}$ has been employed to visualize the geometric and electronic features of the different stationary points.

In this investigation, all elementary reactions begin with the formation of a pre-reactive complex (CR), which is in equilibrium with the reactants and occurs before the transition state and the release of the corresponding products. Although these pre-reactive complexes do not play any role in the regioselectivity of the corresponding elementary reaction, the fact that we have found them in each elementary process has allowed us to consider reaction (9) in our kinetic study

$$
\mathrm{RSSH}+{ }^{\bullet} \mathrm{OH} \rightleftharpoons \mathrm{CR} \rightarrow \text { Products }
$$

According to this reaction scheme, and taking into account the fact that all transition states lie higher in terms of free energy than the reactants (see Table 1 and Table S1, ESI $\dagger$ ), the kinetic model employed in the calculation of the rate constants has been done according to eqn (1).

$$
k_{\mathrm{I}}=\frac{k_{1}}{k_{-1}} k_{2}=K_{\mathrm{eq}} k_{2}
$$

where $K_{\text {eq }}$ is the equilibrium constant of the pre-reactive complex and $k_{2}$ is the rate constant of the unimolecular reaction between 
Table 1 Relative energies, energies plus ZPE, enthalpies at $298 \mathrm{~K}$ and free energies at $298 \mathrm{~K}$ (all values in $\mathrm{kcal} \mathrm{mol}^{-1}$ ), for the reaction between $\mathrm{HSSH}$ and $\cdot \mathrm{OH}^{a, b}$

\begin{tabular}{|c|c|c|c|c|}
\hline & $\Delta E$ & $\Delta(E+\mathrm{ZPE})$ & $\Delta H(298 \mathrm{~K})$ & $\Delta G(298 \mathrm{~K})$ \\
\hline \multicolumn{5}{|c|}{$\mathrm{HSSH}+{ }^{\bullet} \mathrm{OH} \rightarrow \mathrm{HSOH}++^{\bullet} \mathrm{SH}$ (reaction (1)) } \\
\hline $\mathrm{HSSH}+\mathrm{OH}$ & 0.00 & 0.00 & 0.00 & 0.00 \\
\hline CRFTS1a & -4.51 & -2.94 & -3.23 & 3.99 \\
\hline FTS1a & 3.89 & 6.27 & 5.18 & 14.56 \\
\hline CPFTS1a & -10.82 & -8.55 & -8.67 & -2.39 \\
\hline CRHTS5a & -3.21 & -1.89 & -2.00 & 4.22 \\
\hline CRHTS5a & 1.69 & 4.44 & 3.27 & 12.75 \\
\hline CRHTS5a & -10.82 & -8.55 & -8.67 & -2.39 \\
\hline CRBTS1a & -3.21 & -2.13 & -2.09 & 3.39 \\
\hline BTS1a & -3.57 & -1.51 & -2.39 & 6.51 \\
\hline CPBTS1a & -13.58 & -10.32 & -11.04 & -2.25 \\
\hline CRBTS1b & -4.51 & -2.94 & -3.23 & 3.99 \\
\hline BTS1b & -3.93 & -1.76 & -2.71 & 6.28 \\
\hline CPBTS1b & -12.87 & -9.82 & -10.46 & -1.87 \\
\hline $\mathrm{HSOH}+\bullet \mathrm{SH}$ & -7.67 & -6.43 & -6.57 & -6.56 \\
\hline \multicolumn{5}{|c|}{$\mathrm{HSSH}+{ }^{\bullet} \mathrm{OH} \rightarrow \mathrm{HSS}^{\bullet}+\mathrm{H}_{2} \mathrm{O}($ reaction (3)) } \\
\hline $\mathrm{HSSH}++^{\bullet} \mathrm{OH}$ & 0.00 & 0.00 & 0.00 & 0.00 \\
\hline CRHTS3a & -4.51 & -2.94 & -3.23 & 3.99 \\
\hline HTS3a & -1.38 & -1.40 & -2.11 & 5.82 \\
\hline CPHTS3a & -49.19 & -45.37 & -45.21 & -40.26 \\
\hline CRHTS3b & -3.21 & -2.13 & -2.09 & 3.39 \\
\hline HTS3b & -1.64 & -1.61 & -2.35 & 5.64 \\
\hline CPHTS3b & -51.38 & -47.07 & -47.27 & -40.36 \\
\hline CRPTS3a & -4.51 & -2.94 & -3.23 & 3.99 \\
\hline PTS3a & 2.03 & 2.53 & 1.43 & 10.54 \\
\hline CPPTS3a & -51.38 & -47.07 & -47.27 & -40.36 \\
\hline $\mathrm{HSS}^{\bullet}+\mathrm{H}_{2} \mathrm{O}$ & -45.83 & -43.29 & -43.22 & -43.75 \\
\hline \multicolumn{5}{|c|}{$\begin{array}{l}{ }^{a} \text { Energies computed at the CCSD }(\mathrm{T}) / \text { aug-cc-pV }(\mathrm{T}+\mathrm{d}) \mathrm{Z} / / \mathrm{QCISD} / 6-311+ \\
\mathrm{G}(2 \mathrm{df}, 2 \mathrm{p}) \text { level. The ZPE values and the enthalpic and entropic correc- } \\
\text { tions are computed at the BH\&HLYP } / 6-311+\mathrm{G}(2 \mathrm{df}, 2 \mathrm{p}) \text { level. }{ }^{b} \text { CRHTS3a } \\
\text { CRBTS1b = CRHTS3a = CRPTS34a; CRFTS1b = CRBTS1a = CRHTS3b; } \\
\text { CPFTS1a = CPFTS1b; CPHTS3b = CPPTS3a. }\end{array}$} \\
\hline
\end{tabular}

the pre-reactive complex and the reaction product. The $K_{\mathrm{eq}}$ values have been calculated according to eqn (2).

$$
K_{\text {eq }}=\frac{Q_{\mathrm{RSSH} \cdot \mathrm{OH}}}{Q_{\mathrm{RSSH}} Q_{\mathrm{OH}}} \mathrm{e}^{\frac{-\left(E_{\mathrm{C}}-E_{\mathrm{R}}\right)}{k_{\mathrm{B}} T}}
$$

And for $k_{2}$ we have used conventional transition state theory and canonical variational transition state theory (CVTST), ${ }^{48-50}$ following eqn (3).

$$
k_{2}=\kappa \frac{k_{\mathrm{B}} T}{h} \frac{Q_{\mathrm{GT}}\left(S^{*}\right)}{Q_{\text {Complex }}} \mathrm{e}^{\frac{-V\left(S^{*}\right)}{k_{\mathrm{B}} T}}
$$

For the CVTST calculations, we have employed the VTST-ISPE approach, where the energies have been computed at $\operatorname{CCSD}(\mathrm{T}) /$ aug-cc-pV $(\mathrm{T}+\mathrm{d}) \mathrm{Z}$ level of theory whereas the hessian matrices at the stationary points and at selected points along the reaction path have been calculated at the BH\&HLYP/6-311+G(2df,2p) level of theory. The computed values for all elementary reactions investigated are given in the ESI. $\dagger$ In all the cases, the partition functions have been calculated from a rigid rotor harmonic oscillator approximation. In eqn (3), $S^{*}$ is the free energy maximum along the reaction path at temperature $T, Q_{\text {Complex }}$ is the partition function of the pre-reactive complex, $Q_{\mathrm{GT}}\left(S^{*}\right)$ is the generalized transition state partition function and $V\left(S^{*}\right)$ is the potential energy and $\kappa$ is the tunneling parameter, that has been computed with the small curvature approach and has been considered in all reactions involving the hydrogen transfer processes. The Polyrate $^{51}$ program has been used for the kinetic study.

\section{Results and discussion}

In this investigation, we have found different kinds of reaction mechanisms for the reaction of ${ }^{\bullet} \mathrm{OH}$ with a set of $\mathrm{RSSH}(\mathrm{R}=-\mathrm{H}$, $-\mathrm{CH}_{3},-\mathrm{NH}_{2},-\mathrm{C}(\mathrm{O}) \mathrm{OH},-\mathrm{CN}$, and $\left.-\mathrm{NO}_{2}\right)$ and for the reactions between their products as well. All through this text, we have named the different elementary reactions following their transition state; that is, a name starting with a capital letter that identifies the kind of reaction mechanism, followed by the letters TS, a number corresponding to the reaction, and the letters a, b, and so on to differentiate different elementary reactions. The different reaction mechanisms and the corresponding identifying letters are: frontside attack of the ${ }^{\bullet} \mathrm{OH}$ on a sulfur atom (FS); backside attack of ${ }^{\bullet} \mathrm{OH}$ on a sulfur atom (BS); hydrogen atom transfer $(\mathrm{H})$, and proton-coupled electron transfer (P). Thus, for instance, BSTS1a and BTS1b identify two different transition states corresponding to a backside attack of reaction (1), and PTS3a identifies a transition state of reaction (3) that takes place through a proton-coupled electron transfer mechanism. In a similar way, the pre-reactive complexes and post-reactive complexes are named by adding the letters CR and CP respectively, followed by the name of the transition state identifying the elementary reaction considered.

\section{The reaction of ${ }^{\bullet} \mathrm{OH}$ with $\mathrm{HSSH}$}

The simplest reaction we have considered is the oxidation of hydrogen disulfide by the hydroxyl radical. In Fig. 1 we have plotted a schematic potential energy surface of this reaction and Table 1 contains the corresponding relative energies. Fig. 2 shows the most relevant electronic features of the elementary reactions involved in this process. Regarding the attack of the hydroxyl radical on sulfur atoms, it must be pointed out that both sulfur atoms in $\mathrm{HSSH}$ are equivalent so that reactions (1) and (2) are the same in this case. This reaction leads to the formation of $\mathrm{HSOH}$ and ${ }^{\bullet} \mathrm{SH}$. The abstraction of one hydrogen atom of $\mathrm{HSSH}$ by the ${ }^{\bullet} \mathrm{OH}$ produces $\mathrm{HSS}^{\bullet}$ and $\mathrm{H}_{2} \mathrm{O}$ (reaction (3)).

All elementary reactions investigated are mediated by the existence of a pre-reactive and a post-reactive complex occurring before and after the corresponding transition state. We have found three different pre-reactive complexes with binding energies ranging between 1.89 and $2.95 \mathrm{kcal} \mathrm{mol}^{-1}$ (see Table 1). Fig. S1 (ESI $\dagger$ ) shows that in these complexes the two moieties ( $\mathrm{HSSH}$ and ${ }^{\bullet} \mathrm{OH}$ ) are held together by a van der Waals interaction between the $\mathrm{O}$ and one $\mathrm{S}$ atom with distances ranging between 2.668 and $2.996 \AA$ and HSS angles ranging between 84.3 and $110.3^{\circ}$.

For reaction (1), the ${ }^{\bullet} \mathrm{OH}$ can interact with the sulfur atom in two different ways, namely following a frontside attack mechanism or a backside attack process, in a similar way as described for the attack of methyl radical on the S-S bond by Krenske and 


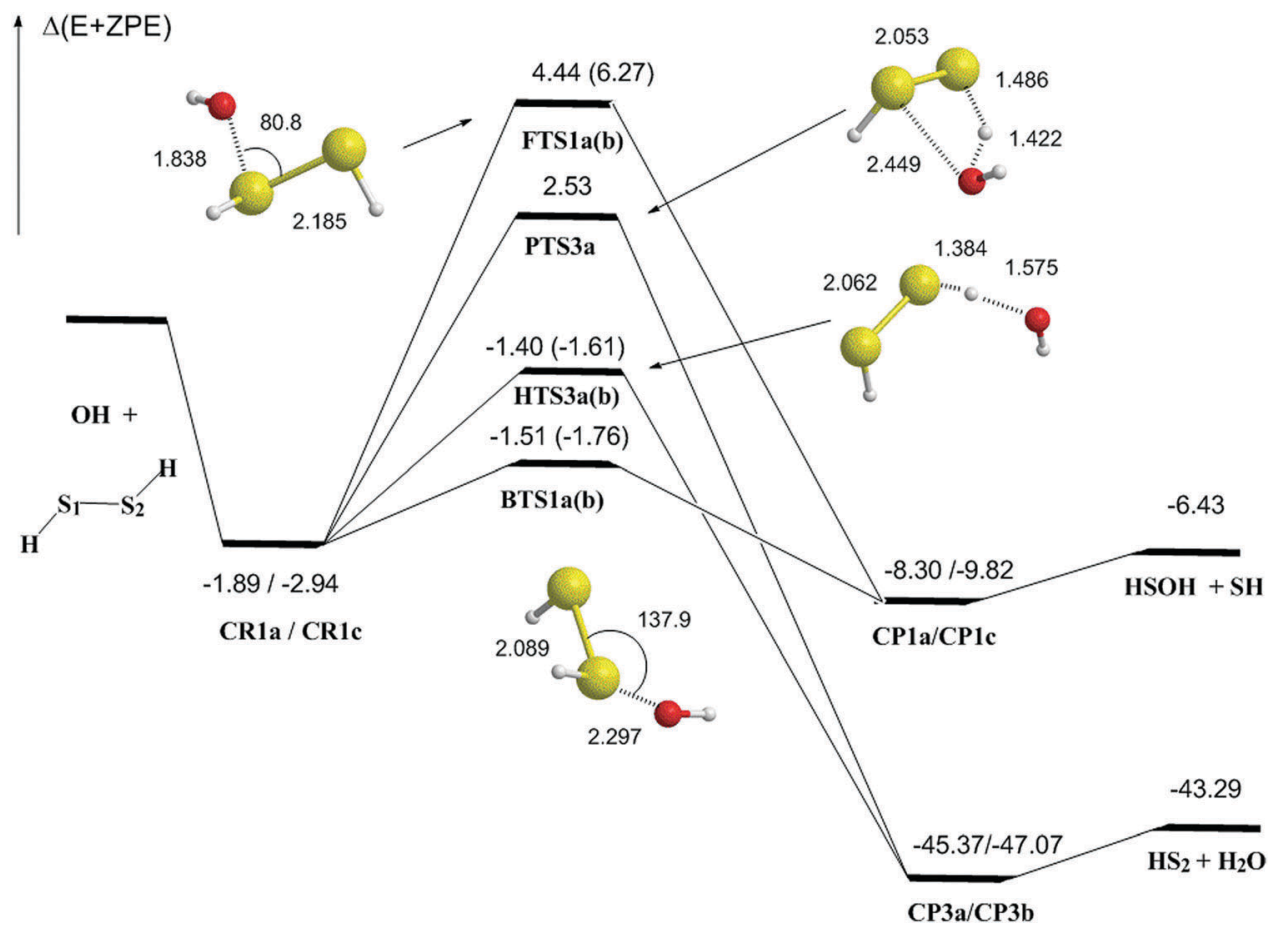

Fig. 1 Schematic potential energy surface of the $\bullet \mathrm{OH}+\mathrm{HSSH}$ reaction. Only some of the transition states are drawn.

co-workers. ${ }^{8}$ In the present investigation, we have found two elementary reactions for both the frontside and the backside attack of the ${ }^{\bullet} \mathrm{OH}$ on the sulfur atom, depending on the side in which the ${ }^{\bullet} \mathrm{OH}$ approaches the disulfide bond. Fig. 1 and Table 1 show that, after forming the pre-reactive complexes, the reaction paths involved in the frontside attack go through the FTS1a and FTS1b transition states which lie 4.44 and $6.27 \mathrm{kcal} \mathrm{mol}^{-1}$ above the energy of the reactants. Our calculations also show that the reaction paths going through the backside attack require to surmount much smaller energy barriers, and the corresponding transition states, BTS1a and BTS1b, lie 1.76 and $1.51 \mathrm{kcal} \mathrm{mol}^{-1}$ below that of the reactants, and just slightly above the energy of the pre-reactive complexes. After the transition states, each elementary reaction goes through a post-reactive complex lying between $(-8.55$ and $-10.32 \mathrm{kcal} \mathrm{mol}^{-1}$ ) and before the formation of the $\mathrm{HSOH}$ and - $\mathrm{SH}$ products. The calculated reaction energy is $-6.43 \mathrm{kcal} \mathrm{mol}^{-1}$ and the reaction enthalpy $-6.57 \mathrm{kcal} \mathrm{mol}^{-1}$.

The most relevant geometric features of the frontside and backside transition states are displayed in Fig. 1. In the frontside attack, ${ }^{\bullet} \mathrm{OH}$ approaches almost perpendicularly to the $\mathrm{S}-\mathrm{S}$ bond $\left(\mathrm{O}-\mathrm{S}-\mathrm{S}\right.$ angle at near $\left.80^{\circ}\right)$ and the $\mathrm{O}-\mathrm{S}$ and the $\mathrm{S}-\mathrm{S}$ distances are close to $1.8 \AA$ and $2.2 \AA$, respectively, in the FTS1a and FTS1b transition states. These geometrical parameters suggest a late transition state, which is confirmed by the electronic features displayed in Fig. 2a. The picture of the SOMO orbital shows that the unpaired electron lies mainly over the S1 atom and the spin densities are $s=0.63$ at S1 and $s=0.14$ at the oxygen atom of the attacking radical. Moreover, AIM analysis of the wave function shows that the value of the density $\rho$ and the laplacian of the density $\nabla^{2} \rho$ of the O-S bond being formed are 0.1516 and -0.0575 a.u. respectively, indicating that the negative charge is being concentrated over the $\mathrm{O}-\mathrm{S}$ bond which is being formed.

In contrast, the backside attack shows a more linear geometry and the transition states (BTS1a and BTS1b) are more reactant-like. The corresponding $\mathrm{O}-\mathrm{S}$ distances are much larger, 2.09 and $2.30 \AA$; the S-S distances are 2.104 and $2.089 \AA$; the OSS angles are 139.9 and $137.9^{\circ}$. Fig. $2 \mathrm{~b}$ shows that, at the transition state, the unpaired electron is mainly located over the oxygen atom of the hydroxyl $(s=0.77)$ whereas the spin density over the $\mathrm{S} 1$ atom is $s=0.18$. The AIM analysis of the wave function gives values of $\rho$ and $\nabla^{2} \rho$ of 0.0739 and 0.1627 a.u., respectively, indicating a depleted charge concentration over the $\mathrm{O}-\mathrm{S}$ bond being formed, that is in agreement with an early transition state. These electronic features indicate that the backside transition states should have energies close to those of their pre-reactive complexes so that a prompt reaction takes place. At this point, it is worth mentioning that the geometric features of these transition states have many similarities with the corresponding frontside and backside attack transition states of the reaction between the methyl radical and several disulfides, reported by Krenske and co-workers. ${ }^{8}$

Our results regarding the reaction mechanisms allow us to compute the rate constants for these processes. At $298 \mathrm{~K}$ the calculated values are $5.70 \times 10^{9} \mathrm{M}^{-1} \mathrm{~s}^{-1}$ for the backside reaction and $2.17 \times 10^{5} \mathrm{M}^{-1} \mathrm{~s}^{-1}$ for the frontside process. The drastic kinetic difference clearly suggests that reaction (1) ( ${ }^{\circ} \mathrm{OH}$ substitution at the disulfide bond) takes place exclusively through a backside attack mechanism.

The hydrogen abstraction reaction (reaction (3)) is computed to be exothermic by $43.22 \mathrm{kcal} \mathrm{mol}^{-1}$. For this reaction, we have 
(a)

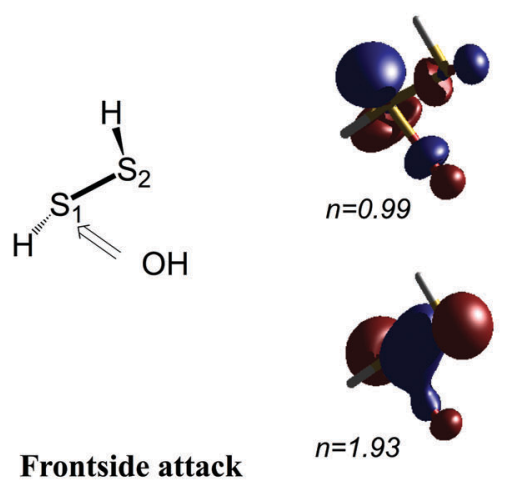

(c)

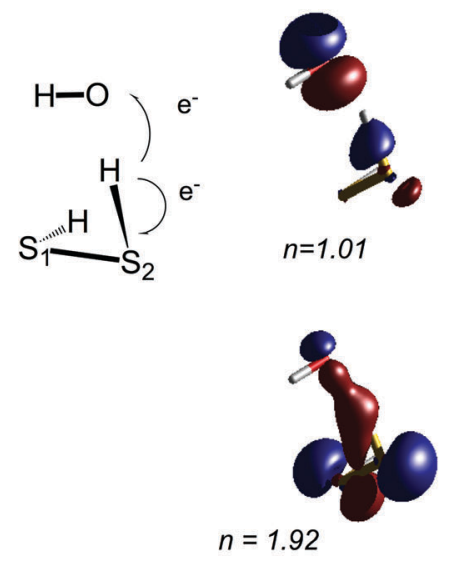

(b)

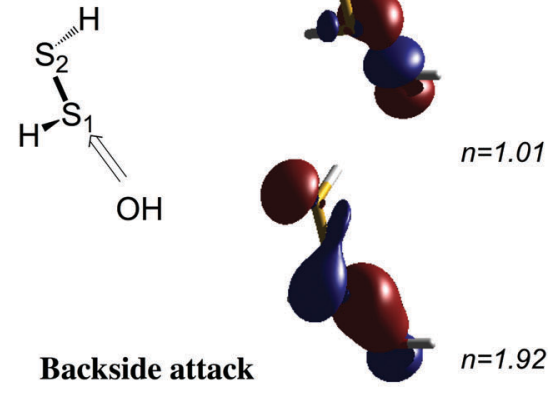

(d)
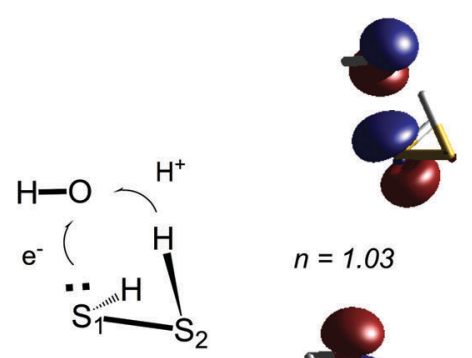

$n=1.03$

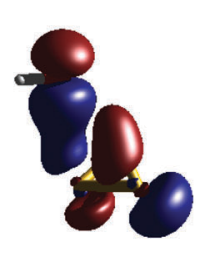

$n=1.91$

Hydrogen atom transfer

Proton coupled electron transfer

Fig. 2 Electronic features of the different elementary processes involved in the $\bullet \mathrm{OH}+\mathrm{HSSH}$ reaction. The $\mathrm{HOMO}$ and $\mathrm{SOMO}$ orbitals, computed at the $\mathrm{QCISD} / 6-311+\mathrm{G}(2 \mathrm{df}, 2 \mathrm{p})$ level, are drawn along with the occupation numbers.

found two different reaction processes involving very different electronic features. The first one takes place through a hydrogen atom transfer mechanism (hat), which involves the simultaneous breaking of the (HS)S-H bond and forming the $\mathrm{H}-\mathrm{O}(\mathrm{H})$ bond. Here, we have found two elementary reaction paths. Their transition states (HTS3a and HTS3b) differ in the relative position of the ${ }^{\bullet} \mathrm{OH}$ moiety with respect to the $\mathrm{HSSH}$ and their energies lie -1.40 and $-1.61 \mathrm{kcal} \mathrm{mol}^{-1}$ relative to the reactants, respectively. Fig. 2c shows the typical electronic features of the hydrogen atom transfer process, where the unpaired electron (SOMO orbital) is shared between the oxygen and sulfur atoms into which the hydrogen atom is being transferred (with spin densities $s=0.85$, and 0.19 , respectively) while the HOMO orbital shows an interaction between all the atoms involved in this process.

The second one corresponds to a proton-coupled electron transfer mechanism (pcet). It occurs through the PTS3a transition state that is computed to lie $2.53 \mathrm{kcal} \mathrm{mol}^{-1}$ higher (see Table 1). Its features are drawn in Fig. 2d, which shows that at the transition state (PTS3a), the ${ }^{\bullet} \mathrm{OH}$ approaches the $\mathrm{HSSH}$ in such a way that the lone pair over the oxygen atom of the radical moiety is directed towards one hydrogen atom of the disulfide moiety (the one bonded to S1), whereas the unpaired electron over the ${ }^{\bullet} \mathrm{OH}$ interacts with the sulfur atom linked to the other $\mathrm{H}$ atom (S2), so that there is a shift of one electron of this S atom to the $\mathrm{O}$ atom and simultaneously, the proton bonded to $\mathrm{S} 1$ is transferred to the ${ }^{\bullet} \mathrm{OH}$. The HOMO and SOMO orbitals clearly show the electronic interaction between the $\mathrm{S} 2$ atom and the oxygen atom into which the electron is being transferred. The spin densities over the $\mathrm{S} 2$ and $\mathrm{O}$ atoms at the transition state are 0.45 and 0.55 respectively. These electronic features characterizing this process are similar to those described for the gas-phase oxidation of several acids by ${ }^{\bullet} \mathrm{OH}$ or for the oxidation of $\mathrm{HNO}_{3}$ by $\mathrm{NH}_{2} \cdot{ }^{52-58}$ It is worth mentioning that the $\mathrm{H}$ transfer process has the same features as the oxidation of the $\mathrm{H}_{2} \mathrm{O}_{2}$ by ${ }^{\bullet} \mathrm{OH},{ }^{59}$ although in the case of $\mathrm{HSSH}$, it has a smaller energy barrier and a better $\mathrm{H}$ transfer ability associated with the $\mathrm{SH}$ group. In addition, it is remarkable that the sulfur atom can open a new reaction channel such as pcet, which does not occur for the valence isoelectronic compound $\mathrm{H}_{2} \mathrm{O}_{2}$. Another example is that pcet has been also observed for the $\mathrm{HSOH}+{ }^{\bullet} \mathrm{OOH}$ reaction. ${ }^{27}$

At $298 \mathrm{~K}$, the computed rate constants are $2.99 \times 10^{10} \mathrm{M}^{-1} \mathrm{~s}^{-1}$ for the hat process, and $3.49 \times 10^{8} \mathrm{M}^{-1} \mathrm{~s}^{-1}$ for the pcet reaction, 
indicating that the proton-coupled electron transfer elementary reaction plays a minor role in the reaction of ${ }^{\bullet} \mathrm{OH}$ with $\mathrm{HSSH}$.

The overall rate constant for the reaction between ${ }^{\bullet} \mathrm{OH}$ and $\mathrm{HSSH}$, which includes reactions (1) and (3), is $3.59 \times$ $10^{10} \mathrm{M}^{-1} \mathrm{~S}^{-1}$ at $298 \mathrm{~K}$ and the corresponding branching ratios are $16 \%$ and $84 \%$ for the attack of ${ }^{\bullet} \mathrm{OH}$ on the $\mathrm{S}$ atom (reactions (1)) and for the hydrogen abstraction (reaction (3)), respectively. The rate constants and branching ratios at different temperatures are presented in Table S2 of the ESI. $\dagger$

The reactions between the ${ }^{\bullet} \mathrm{OH}$ and the $\mathrm{RSSH}\left(\mathrm{R}=\mathrm{CH}_{3}, \mathrm{NH}_{2}\right.$, $\mathrm{COOH}, \mathrm{CN}$ and $\mathrm{NO}_{2}$ )

The main goal of this study is to investigate the inductive effects of substituents on the reactivity between ${ }^{\bullet} \mathrm{OH}$ and $\mathrm{RSSH}$, viz. $\mathrm{RSSH}\left(\mathrm{R}=-\mathrm{CH}_{3},-\mathrm{NH}_{2},-\mathrm{C}(\mathrm{O}) \mathrm{OH},-\mathrm{CN}\right.$, and $\left.-\mathrm{NO}_{2}\right)$. In these systems, the two sulfur atoms experience a different chemical environment; therefore, their reactivity toward the ${ }^{\bullet} \mathrm{OH}$ might be different, resulting in the selectivity toward a certain sulfur atom in the disulfide bond. For each RSSH compound, we have investigated the disulfide bond cleavage and hydrogen atom abstraction by ${ }^{\bullet} \mathrm{OH}$. For the reactions of ${ }^{\bullet} \mathrm{OH}$ with $\mathrm{H}_{3} \mathrm{CSSH}$ and with $\mathrm{HO}(\mathrm{O}) \mathrm{CSSH}$, additional reaction channels have been studied.

The general scheme for the potential energy surface for the reactions of ${ }^{\bullet} \mathrm{OH}$ and $\mathrm{RSSH}$ has the same trends as those shown in Fig. 1 for the reaction of $\mathrm{OH}$ and $\mathrm{HSSH}$, but for these asymmetric disulfides, the elementary reactions of the ${ }^{\bullet} \mathrm{OH}$ attacking the two sulfur atoms are now at a different chemical environment. The sulfur atom linked to the hydrogen atom is annotated as S1 and the sulfur atom bonded to the R group is labeled as S2. All elementary reactions are mediated by pre-reactive and post-reactive complexes with their corresponding relative energies collected in Table S1 (ESI $\dagger$ ). In Fig. 3 we have plotted the relative energies of the transition states relative to that of the reactants for all elementary reactions involved in reactions (1), (2) and (3). We observe two main trends: firstly, the backside attack of - $\mathrm{OH}$ on the $\mathrm{S}$ atoms is always preferred to the frontside attack; secondly, there are great differences between the attack of the ${ }^{\bullet} \mathrm{OH}$ on each of the two sulfur atoms (see Fig. 3a and b). Regarding the attack of ${ }^{\bullet} \mathrm{OH}$ on $\mathrm{S} 1$ (reaction (1)), Fig. 3a shows that all transition states involving the backside mechanism (BTS1a and BTS1b) have almost the same energy of the reactants or lie below, with values ranging between 0.07 and $-2.42 \mathrm{kcal} \mathrm{mol}^{-1}$. The transition states involving the frontside mechanism (FTS1a and FTS1b) lie much higher in energy, up to $10.95 \mathrm{kcal} \mathrm{mol}^{-1}$. In all elementary reactions, the attack of ${ }^{\bullet} \mathrm{OH}$ to $\mathrm{S} 1$ leads to the formation of the $\mathrm{HSOH}+\bullet$ SR products.

On the other hand, Fig. 3b shows more mixed results for the attack of ${ }^{\bullet} \mathrm{OH}$ on S2 (reaction (2)). A more detailed analysis of these results indicates that the transition states (BTS2a and BTS2b) lie between -3.22 and $-5.63 \mathrm{kcal} \mathrm{mol}^{-1}$ for the reactions having EDGs $\left(-\mathrm{CH}_{3}\right.$ and $\left.-\mathrm{NH}_{2}\right)$ but between -0.25 and $1.62 \mathrm{kcal} \mathrm{mol}^{-1}$ for the reactions with EWGs $(-\mathrm{C}(\mathrm{O}) \mathrm{OH},-\mathrm{CN}$, and $-\mathrm{NO}_{2}$ ). Regarding the frontside attack, Fig. $3 \mathrm{~b}$ and Table $\mathrm{S} 1$ (ESI $\dagger$ ) show that FTS2a and FTS2b lie between -1.32 and $1.77 \mathrm{kcal} \mathrm{mol}^{-1}$ for $\mathrm{R}=-\mathrm{CH}_{3},-\mathrm{NH}_{2}$, and $-\mathrm{NO}_{2}$, but 4.12 and $6.09 \mathrm{kcal} \mathrm{mol}^{-1}$ for $\mathrm{R}=-\mathrm{C}(\mathrm{O}) \mathrm{OH}$ and $-\mathrm{CN}$. It is worth pointing out that for $\mathrm{R}=-\mathrm{NO}_{2}$, (a)
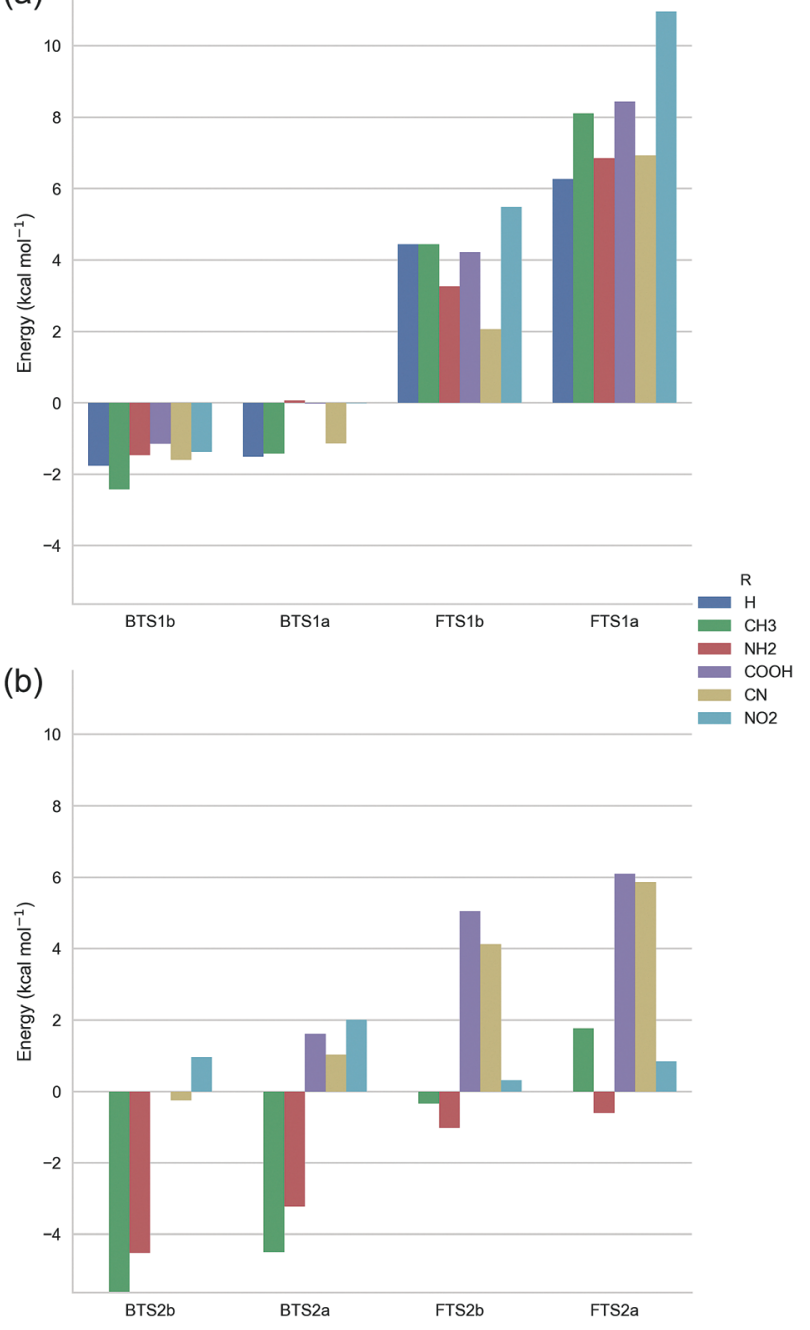

(c)

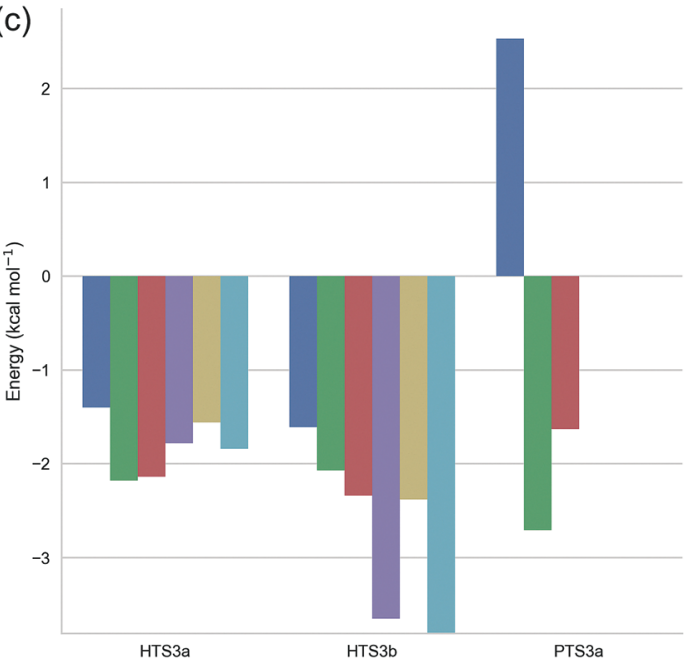

Fig. 3 Relative energies (in $\mathrm{kcal} \mathrm{mol}^{-1}$ ) of the transition states, with respect to the energies of the reactants, for the processes involved in (a) reactions (1), (b) reaction (2), and (c) reaction (3).

the frontside attack transition states lie lower in energy than the backside attack transition states. 
With respect to the reaction mechanism, all elementary reactions lead to the formation of ${ }^{\bullet} \mathrm{SH}$ and HOSR (reaction (2)), but in the case of $\mathrm{R}=-\mathrm{NO}_{2}$, the elementary reactions occurring through the frontside attack on $\mathrm{S} 2$ involve an $\mathrm{S}_{\mathrm{N}}$ substitution (reaction (10), transition states FTS8a and FTS8b), and lead to the formation of OHSSH and $\mathrm{NO}_{2}$.

$$
\mathrm{NO}_{2} \mathrm{SSH}+\bullet \mathrm{OH} \rightarrow \mathrm{HSSOH}+\mathrm{NO}_{2}
$$

These results clearly indicate that the inductive effect of the $\mathrm{R}$ substituent has a much greater impact on the $\mathrm{S}$ atom to which it is directly linked regarding the attack of the ${ }^{\bullet} \mathrm{OH}$.

The geometric and electronic features of these transition states are very similar to those discussed in the previous section of the attack of the ${ }^{\bullet} \mathrm{OH}$ on the $\mathrm{S}$ atom of HSSH. In Table 2, we have collected the main geometrical parameters of selected transition states and Table S3 of the ESI $\dagger$ displays the main topological parameters of the corresponding wave functions. These tables show that in the backside attack, the ${ }^{\bullet} \mathrm{OH}$ approaches the sulfur atom in quite a linear manner and the transition states are reactant like. The distances between the approaching oxygen atom and the sulfur atom are between 2.074 and $2.269 \AA$ and the attack angles are between $123.6^{\circ}$ and $150.1^{\circ}$ (see Table 2). The topological parameters of the corresponding wave functions ( $\rho$ and $\nabla^{2} \rho$ ) show the same trends as discussed in the previous section for the backside attack of the • $\mathrm{OH}$ on the HSSH, namely very small (less than zero) values of $\rho$ and positive values for $\nabla^{2} \rho$ indicating a depleted charge density in the bond being formed (see Table S3, ESI $\dagger$ ), suggesting a low energy barrier. On the other hand, in the frontside attack, the - $\mathrm{OH}$ approaches the RSSH in a perpendicular manner and the transition states are more product-like. The $\mathrm{O}-\mathrm{S}$ distances range between $1.775 \AA$ and $1.914 \AA$ and the OSS angles vary between $78.2^{\circ}$ and $101.4^{\circ}$. The topological parameters of the wave functions show similar trends as discussed for the frontside attack transition states in the reaction of ${ }^{\bullet} \mathrm{OH}$ with $\mathrm{HSSH}$ as discussed in the previous section (see Table S3, ESI $\dagger$ ).

With respect to the hydrogen abstraction process, involving the formation of $\mathrm{RSS}^{\bullet}$ and $\mathrm{H}_{2} \mathrm{O}$ (reaction (3)), Fig. 3c shows that all transition states lie energetically lower than those of the reactants, between -0.55 and $-3.81 \mathrm{kcal} \mathrm{mol}^{-1}$. This observation suggests that $\mathrm{H}$ abstraction competes or it is even kinetically more favorable than the attack of the ${ }^{\bullet} \mathrm{OH}$ on any $\mathrm{S}$ atom for certain RSSH compounds. Regarding the reaction mechanisms, we have found hydrogen atom transfer (hat) elementary reactions for all the models investigated. In fact, we have found two elementary reactions for the ${ }^{\bullet} \mathrm{OH}$ hat abstraction process in each RSSH (with transition states HTS3a and HST3b), which differ in the orientation of the ${ }^{\bullet} \mathrm{OH}$ moiety with respect to the $\mathrm{RSSH}$ moiety. However, in the case of the electron donating substitutes we have also found proton-coupled electron transfer processes (pcet) involved in the $\mathrm{H}$ transfer reactions. For $\mathrm{R}=-\mathrm{CH}_{3}$, the pcet transition states (PTS3a and PTS3b) lie lower in energy than the hat ones (see Fig. 3c and Table S1, ESI $\dagger$ ) so that the hydrogen abstraction process takes place mostly through a pcet mechanism. The fact that we have not found the pcet reaction mechanisms of reaction (3) for $\mathrm{R}=-\mathrm{C}(\mathrm{O}) \mathrm{OH},-\mathrm{CN}$, and $-\mathrm{NO}_{2}$, is attributed to the electron withdrawing effect of these substituents. This inductive character implies that $\mathrm{S} 2$ possesses a smaller negative charge which hampers the ability of transferring one electron from $\mathrm{S} 2$ to the oxygen atom of the ${ }^{\bullet} \mathrm{OH}$ moiety consequently preventing the pcet reaction.

Beyond the study of reactions involving the attack on the sulfur atoms and the abstraction of the RSS-H atom by the ${ }^{\bullet} \mathrm{OH}$ discussed above, we have also investigated additional reaction processes for $\mathrm{R}=-\mathrm{CH}_{3}$, and $-\mathrm{C}(\mathrm{O}) \mathrm{OH}$, according to reactions (11) and (12), respectively.

$$
\begin{gathered}
\mathrm{H}_{3} \mathrm{CSSH}+{ }^{\bullet} \mathrm{OH} \rightarrow{ }^{\bullet} \mathrm{CH}_{2} \mathrm{SSH}+\mathrm{H}_{2} \mathrm{O} \\
\mathrm{HO}(\mathrm{O}) \mathrm{CSSH}+{ }^{\bullet} \mathrm{OH} \rightarrow \mathrm{HSSC}(\mathrm{O}) \mathrm{O}^{\bullet}+\mathrm{H}_{2} \mathrm{O}
\end{gathered}
$$

Reaction (11) implies the abstraction of a hydrogen atom of the $-\mathrm{CH}_{3}$ group by the ${ }^{\bullet} \mathrm{OH}$, which takes place through a hat process and is computed to be exothermic by $21.17 \mathrm{kcal} \mathrm{mol}^{-1}$. For this process, we have found two elementary reactions, the computed transition states of which (HTS11a and HTS1b) lie just 0.02 and $0.72 \mathrm{kcal} \mathrm{mol}^{-1}$ above the energy of the reactants. Again, the two transition states differ in the relative orientation of the ${ }^{\circ} \mathrm{OH}$ group with respect to the $\mathrm{CH}_{3} \mathrm{SSH}$ moiety. In addition, ${ }^{\bullet} \mathrm{CH}_{2} \mathrm{SSH}$ can decompose into ${ }^{\bullet} \mathrm{SH}$ and $\mathrm{H}_{2} \mathrm{CS}$, which is computed to be endothermic by $17.59 \mathrm{kcal} \mathrm{mol}^{-1}$ (see Table S1, $\mathrm{ESI} \dagger)$. It is here worth mentioning that reaction (11) has the same features as the oxidation of $\mathrm{CH}_{3} \mathrm{OOH}$ by ${ }^{\circ} \mathrm{OH}$, producing ${ }^{\bullet} \mathrm{CH}_{2} \mathrm{OOH}$ and $\mathrm{H}_{2} \mathrm{O} .{ }^{60}$ However, ${ }^{\circ} \mathrm{CH}_{2} \mathrm{OOH}$ has been found to be unstable and it readily decomposes into $\mathrm{H}_{2} \mathrm{CO}$ and $\mathrm{H}_{2} \mathrm{O}$,

\begin{tabular}{|c|c|c|c|c|c|c|c|c|c|c|c|c|}
\hline \multirow[b]{2}{*}{$\mathrm{RS}(2) \mathrm{S}(1) \mathrm{H}+{ }^{\bullet} \mathrm{OH}$} & \multicolumn{6}{|c|}{ Attack on S1 } & \multicolumn{6}{|c|}{ Attack on S2 } \\
\hline & OS & SS & $\Varangle$ OSS & OS & SS & $\Varangle$ OSS & OS & SS & $\Varangle$ OSS & OS & SS & $\Varangle$ OSS \\
\hline HSSH & 2.297 & 2.089 & 137.9 & 1.838 & 2.185 & 80.8 & & & & & & \\
\hline $\mathrm{HSSCH}_{3}$ & 2.269 & 2.077 & 133.9 & 1.816 & 2.185 & 81.9 & 2.239 & 2.077 & 123.6 & 1.839 & 2.190 & 82.6 \\
\hline $\mathrm{HSSNH}_{2}$ & 2.133 & 2.126 & 144.9 & 1.818 & 2.231 & 80.1 & 2.109 & 2.097 & 132.6 & 1.775 & 2.190 & 84.8 \\
\hline $\mathrm{HO}(\mathrm{O}) \mathrm{CSSH}$ & 2.167 & 2.098 & 140.0 & 1.887 & 2.171 & 79.6 & 2.187 & 2.109 & 135.6 & 1.821 & 2.147 & 81.3 \\
\hline
\end{tabular}

Table 2 Main geometrical parameters (distances in $\AA$ and angles in degrees) of selected transition states in the attack of the ${ }^{\bullet} \mathrm{OH}$ on the $\mathrm{S}$ atoms of the RSSH compounds ${ }^{a}$

${ }^{a}$ Computed at QCISD/6-311+G(2df,2p). 
which contrasts with the stability of ${ }^{\circ} \mathrm{CH}_{2} \mathrm{SSH}$ computed in this work. ${ }^{61}$

Reaction (12) corresponds to the abstraction of the acidic hydrogen of the carboxylic acid group by the ${ }^{\bullet} \mathrm{OH}$ producing $\mathrm{HSSC}(\mathrm{O}) \mathrm{O}^{\bullet}$ and $\mathrm{H}_{2} \mathrm{O}$. The reaction takes place through a pcet mechanism, in which the ${ }^{\bullet} \mathrm{OH}$ and the carboxylic acid group approach each other so that one electron is transferred from the oxygen atom of the carbonyl group to the oxygen atom of the ${ }^{\bullet} \mathrm{OH}$ moiety and simultaneously, the carboxylic proton is transferred to the ${ }^{\bullet} \mathrm{OH}$. This reaction mechanism has been already described for the gas phase oxidation of $\mathrm{HC}(\mathrm{O}) \mathrm{OH}$ by the $\mathrm{OH}$ radical ${ }^{53}$ For this process, we have found two elementary reactions whose transition states (PTS12a and PTS12b) differ in the relative orientation of the $\mathrm{OH}$ group with respect to $\mathrm{HSSC}(\mathrm{O}) \mathrm{OH}$, and the processes are computed to lie at 1.63 and $1.77 \mathrm{kcal} \mathrm{mol}^{-1}$, respectively. Both elementary reactions are mediated by prereactive and by post-reactive complexes as found in all the reactions investigated in this work. The reaction products are $\mathrm{HSSC}(\mathrm{O}) \mathrm{O}^{\bullet}$ and $\mathrm{H}_{2} \mathrm{O}$ and furthermore, $\operatorname{HSSC}(\mathrm{O}) \mathrm{O}^{\bullet}$ is expected to dissociate into $\mathrm{HSS}^{\bullet}$ and $\mathrm{CO}_{2}$ in a similar way as $\mathrm{HC}(\mathrm{O}) \mathrm{O}^{\bullet}$ decomposes into $\mathrm{H}$ and $\mathrm{CO}_{2},{ }^{53}$ although this process has not been considered in this work.

In Table 3 we have collected the computed rate constants, at $298 \mathrm{~K}$, for the different reactions investigated, along with the corresponding branching ratios. The rate constants and branching ratios for the reaction of $\mathrm{HSSH}$ and ${ }^{\circ} \mathrm{OH}$, discussed in the previous section have been also included. The computed rate constants and branching ratios at different temperatures have been collected in Table S2 of the ESI. $\dagger$ The data in Table 3 suggest that the reactions between ${ }^{\circ} \mathrm{OH}$ and RSSH are very fast, with the computed rate constants ranging from $4.55 \times 10^{12} \mathrm{M}^{-1} \mathrm{~s}^{-1}$ for $\mathrm{R}=-\mathrm{CH}_{3}$, to $3.86 \times 10^{10} \mathrm{M}^{-1} \mathrm{~s}^{-1}$ for $\mathrm{R}=-\mathrm{CN}$. The faster reactions are those involving EDGs. Moreover, there is a difference of almost two orders of magnitude between the faster and the slower reaction. Looking exclusively at the preference of the attack of the ${ }^{\bullet} \mathrm{OH}$ between the two sulfur atoms within RSSH, the results clearly suggest that the reaction is always faster at the electron-rich sulfur atom; that is, when the $\mathrm{R}$ is an EDG the attack occurs primarily on S2 (reaction (2)), whereas for R being an EWG, the attack occurs on mostly S1 (reaction (1)). The rate constants for reaction (2) when R is an EDG are almost two orders of magnitude larger than the rate constants for reaction 1 with R being an EWG. Considering reaction (3), Table 3 shows that when RSSH has an
EDG, the rate constants are higher than when it has an EWG (the differences are up to almost three orders of magnitude between the larger, for $\mathrm{R}=-\mathrm{CH}_{3}$ and the smaller, for $\mathrm{R}=-\mathrm{NO}_{2}$ ). The remaining reactions (10)-(12) have smaller rate constants. Considering all reaction channels, Table 3 shows that the hydrogen atom abstraction (reaction (3)) is the predominant reaction for EWGs, with branching ratios between $91-99 \%$ as compared to the branching ratios of $9-1 \%$ for attacking the disulfide bond. In the case of the EDGs, reactions targeting the disulfide bond are faster than hydrogen abstraction, with branching ratios of $75-83 \%$ for reaction (2) vs. $24-16 \%$ for reaction (3) in the case of $\mathrm{R}=-\mathrm{CH}_{3}$ and $-\mathrm{NH}_{2}$. Here it is also worth pointing out that tunneling effects play an important role. These results clearly show that RSSH indeed are very good $\mathrm{H}$-atom transfer agents in their reactions with the ${ }^{\bullet} \mathrm{OH}$, which is in line with the investigation reported very recently by Chauvin and co-workers, who suggested that these species can act as antioxidants. ${ }^{9}$ However, the present investigation highlights that depending on the nature of $\mathrm{R}$, the attack on the disulfide bond (S-S bond cleavage) does compete with the hydrogen abstraction or even can be the dominant process.

\section{The reactions between $\mathrm{HSOH}$ with $\mathrm{RS}^{\bullet}$ and $\mathrm{RSOH}$ with $\mathrm{HS}^{\bullet}$}

In this work, we have also investigated the reactivity of $\mathrm{HSOH}$ and $\mathrm{RSOH}$ with $\mathrm{RS}^{\bullet}$ and $\mathrm{HS}^{\bullet}$, respectively, which occurs between the products resulting from the attack of the ${ }^{\bullet} \mathrm{OH}$ on the disulfide bond (reactions (1) and (2)). This includes the reactions (4) and (7), that correspond to the reverse reactions (1) and (2) respectively, and the hydrogen transfer process (reactions (5), (6) and (8)). In Table 4 we have collected the relative energies $(\Delta(E+\mathrm{ZPE})$ values) of reactions (5), (6) and (8), whereas the corresponding values of reactions (4) and (7) are derived from Table S1 (ESI $\dagger$ ). Table 5 contains the computed rate constants at $298 \mathrm{~K}$ along with the corresponding branching ratios. Each elementary reaction considered is mediated by the existence of a pre-reactive and a post-reactive complex. In all cases, the $\mathrm{H}$-transfer reactions follow a hat mechanism, and for the elementary processes with $\mathrm{R}=-\mathrm{H},-\mathrm{CH}_{3}$, and $-\mathrm{NH}_{2}$ in reactions (5) and (6) and for all $\mathrm{R}$ in reaction (8) we have found two elementary reactions that differ from each other by the relative orientation of the SR or SH moiety.

Reaction (5) corresponds to the transfer of the hydrogen atom of the $\mathrm{OH}$ group in $\mathrm{HSOH}$ to $\mathrm{RS}^{\bullet}$ leading to the formation

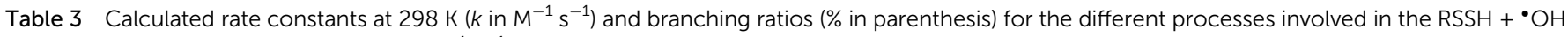
reaction, and the rate constant $\left(k_{\text {total }}\right.$ in $\left.\mathrm{M}^{-1} \mathrm{~s}^{-1}\right)$ for the whole reaction ${ }^{\text {a }}$

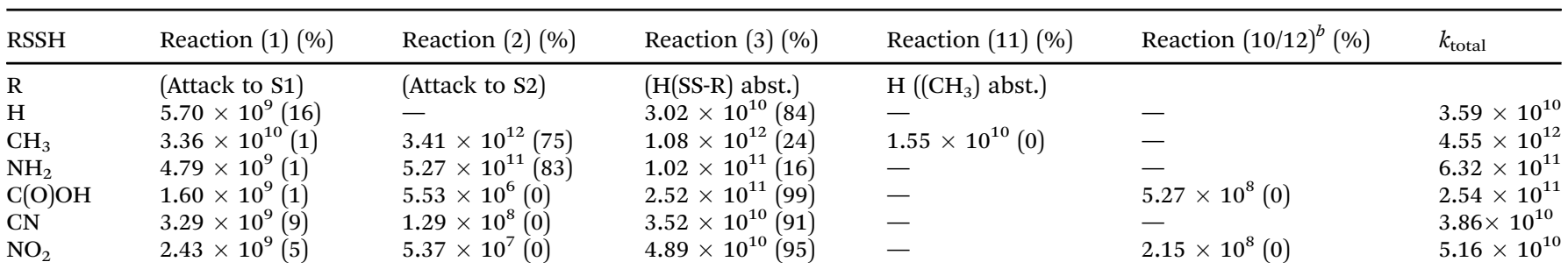

${ }^{a}$ Calculated at the $\mathrm{CCSD}(\mathrm{T}) /$ aug-cc-pV(T+d)Z//QCISD/6-311+G(2df,2p) corrected energies considering the hessian computed at BH\&HLYP/ $6-311+\mathrm{G}(2 \mathrm{df}, 2 \mathrm{p}) .{ }^{b}$ Reaction (12) for $\mathrm{R}=\mathrm{C}(\mathrm{O}) \mathrm{OH}$ and reaction (10) for $\mathrm{R}=\mathrm{NO}_{2}$. 
Table 4 Relative energies $\left(\Delta(E+\mathrm{ZPE})\right.$, in $\left.\mathrm{kcal} \mathrm{mol}^{-1}\right)$ for the stationary points of the elementary reactions involved in the hydrogen transfer in reactions (5), (6) and (8). The two values in each file (plain (a) and in parenthesis (b)), correspond to the relative energies of the two elementary reactions we have found $^{a, b}$

\begin{tabular}{|c|c|c|c|c|c|c|}
\hline $\mathrm{R}$ & $-\mathrm{H}$ & $-\mathrm{CH}_{3}$ & $-\mathrm{NH}_{2}$ & $-\mathrm{COOH}$ & $-\mathrm{CN}$ & $-\mathrm{NO}_{2}$ \\
\hline \multicolumn{7}{|c|}{$\mathrm{HSOH}+\mathrm{RS}^{\bullet} \rightarrow \mathrm{HSO}^{\bullet}+\mathrm{HSR}$ (reaction (5)) } \\
\hline $\mathrm{HSOH}+\mathrm{RS}^{\bullet}$ & $0.00(0.00)$ & $0.00(0.00)$ & $0.00(0.00)$ & 0.00 & 0.00 & 0.00 \\
\hline CRHTS5a (b) & $-4.96(-4.47)$ & $-5.04(-5.04)$ & $-7.13(-67.03)$ & -3.70 & -8.49 & -4.05 \\
\hline HTS5a (b) & $4.85(4.89)$ & $5.20(6.44)$ & $10.52(15.62)$ & 0.87 & -2.74 & 2.22 \\
\hline CPHTS5a (b) & $-18.75(-18.76)$ & $-15.25(-15.25)$ & $-1.10(-1.10)$ & -20.19 & -15.01 & -17.69 \\
\hline $\mathrm{HSO}^{\bullet}+\mathrm{HSR}$ & -16.05 & -11.72 & 2.76 & -14.02 & -8.29 & -5.70 \\
\hline \multicolumn{7}{|c|}{$\mathrm{HSOH}+\mathrm{RS}^{\bullet} \rightarrow \mathrm{HOS}^{\bullet}+\mathrm{HSR}$ (reaction (6)) } \\
\hline $\mathrm{HSOH}+\mathrm{RS}^{\bullet}$ & $0.00(0.00)$ & $0.00(0.00)$ & $0.00(0.00)$ & 0.00 & 0.00 & 0.00 \\
\hline CRHTS6a (b) & $-2.02(-4.96)$ & $-3.27(-5.06)$ & $-5.35(-5.35)$ & -6.55 & -8.49 & -5.87 \\
\hline HTS6a (b) & $0.18(0.40)$ & $0.70(1.78)$ & $9.56(8.72)$ & -0.73 & 0.64 & 0.84 \\
\hline CPHTS6a (b) & $-17.32(-17.31)$ & $-14.93(-14.76)$ & $-3.06(0.80)$ & -14.38 & -12.16 & -11.89 \\
\hline $\mathrm{HOS}^{\bullet}+\mathrm{HSR}$ & -12.96 & -8.62 & 5.86 & -10.92 & -5.19 & -2.60 \\
\hline \multicolumn{7}{|c|}{$\mathrm{RSOH}+\mathrm{HS}^{\bullet} \rightarrow \mathrm{RSO}^{\bullet}+\mathrm{SH}_{2}$ (reaction (8)) } \\
\hline $\mathrm{RSOH}+\mathrm{HS}^{\bullet}$ & $0.00(0.00)$ & $0.00(0.00)$ & $0.00(0.00)$ & $0.00(0.00)$ & $0.00(0.00)$ & $0.00(0.00)$ \\
\hline CRHTS8a (b) & $-4.96(-4.47)$ & $-8.33(-7.16)$ & $-7.94(-7.94)$ & $-5.56(-5.56)$ & $-5.58(-5.58)$ & $-6.08(-6.08)$ \\
\hline HTS8a (b) & $4.85(4.89)$ & $1.48(1.48)$ & $1.69(1.68)$ & $6.33(5.77)$ & $6.55(6.25)$ & $4.82(4.32)$ \\
\hline CPHTS8a (b) & $-18.75(-18.76)$ & $-23.19(-23.21)$ & $-24.86(-24.75)$ & $-14.44(-14.44)$ & $-16.15(-16.15)$ & $-21.22(-21.22)$ \\
\hline $\mathrm{RSO}^{\bullet}+\mathrm{H}_{2} \mathrm{~S}$ & -16.05 & -20.43 & -21.38 & -11.90 & -14.04 & -12.34 \\
\hline
\end{tabular}

of $\mathrm{HSO}^{\bullet}$ and HSR. All these reactions are computed to be exothermic, with values ranging between -5.70 and $-16.05 \mathrm{kcal} \mathrm{mol}^{-1}$, except for $\mathrm{R}=-\mathrm{NH}_{2}$, which is calculated to be endothermic by $2.76 \mathrm{kcal} \mathrm{mol}^{-1}$. Our results displayed in Table 4 show significant differences in the energy barriers depending on the nature of the R substituent. The reactions involving EWGs have small energy barriers, and the corresponding transition states (HTS5) lie between -2.74 (for $\mathrm{R}=-\mathrm{CN}$ ) and 2.22 (for $\mathrm{R}=-\mathrm{NO}_{2}$ ) kcal $\mathrm{mol}^{-1}$ relative to the energies of the reactants. The reactions with EDGs present larger energy barriers with the HTS5b for $\mathrm{R}=-\mathrm{NH}_{2}$ lying up to $15.62 \mathrm{kcal} \mathrm{mol}^{-1}$ above the reactants. These results clearly point out that the ability of accepting a hydrogen atom by $\mathrm{RS}^{\bullet}$ is strongly influenced by the electron inductive nature of $\mathrm{R}$.

Reaction (6) has the same reactants as reaction (5) but the hydrogen transfer taking place is the hydrogen bonded to the sulfur atom in $\mathrm{HSOH}$, forming $\mathrm{HOS}^{\bullet}$ and HSR. These reactions are computed to be exothermic between -2.60 and $-12.96 \mathrm{kcal} \mathrm{mol}^{-1}$ for all $\mathrm{R}$ except for $\mathrm{R}=-\mathrm{NH}_{2}$ which is endothermic by $5.86 \mathrm{kcal} \mathrm{mol}^{-1}$. Table 4 shows that reaction (6) has smaller energy barriers than reaction (5), especially for the compounds having $\mathrm{R}$ as EDGs. Here, the transition states (HTS6 (b)) are computed to lie between -0.73 and $1.78 \mathrm{kcal} \mathrm{mol}^{-1}$ with respect to the energy of the reactants, except for $\mathrm{R}=-\mathrm{NH}_{2}$ which has a higher energy barrier. Compared with reaction (5), the sulfur atom is a much better $\mathrm{H}$ transfer agent than the oxygen atom and in addition, the electron donating character of the $\mathrm{OH}$ group in the $\mathrm{HSOH}$ reactant facilitates the $\mathrm{H}$ transfer ability.

Finally, reaction (8) corresponds to the $\mathrm{H}$ transfer from the $\mathrm{OH}$ group in $\mathrm{RSOH}$ to the $\mathrm{HS}^{\bullet}$, forming $\mathrm{RSO}^{\bullet}$ and $\mathrm{SH}_{2}$. These reactions can be compared to reaction (5) in which the $\mathrm{H}$ atom linked to $\mathrm{S}$ in the reactant is changed by the different $\mathrm{R}$ substitutes. Table 4 shows that the corresponding transition states (HTS8) are computed to lie between 1.48 and $6.55 \mathrm{kcal} \mathrm{mol}^{-1}$ above the reactants. The reactions having smaller energy barriers are those with EDGs $\left(\mathrm{R}=-\mathrm{CH}_{3}\right.$ and $\left.-\mathrm{NH}_{2}\right)$ in contrast to reaction (5), pointing out the importance of the inductive effect of the substitutes too. These reactions are computed to be exothermic between -12.34 and $-21.38 \mathrm{kcal} \mathrm{mol}^{-1}$.

Finally, reactions (4) and (7) have higher energy barriers than reactions (5), (6) and (8) (see Table S1, ESI $\dagger$ ), and consequently, their corresponding rate constants are expected to be much smaller.

Regarding the $\mathrm{HSSOH}+\mathrm{RS}^{\bullet}$ reactions, our results on the kinetic study collected in Table 5 show that the computed rate constants for reaction (5) range between $2.01 \times 10^{9} \mathrm{M}^{-1} \mathrm{~s}^{-1}$ for $\mathrm{R}=-\mathrm{CN}$, and $12 \mathrm{M}^{-1} \mathrm{~s}^{-1}$ for $\mathrm{R}=-\mathrm{NH}_{2}$. Here, it is worth noting that the rate constant for $\mathrm{R}=-\mathrm{CH}_{3}\left(4.28 \times 10^{8} \mathrm{M}^{-1} \mathrm{~s}^{-1}\right)$ is even greater than the rate constant for $\mathrm{R}=-\mathrm{C}(\mathrm{O}) \mathrm{OH}\left(3.40 \times 10^{5} \mathrm{M}^{-1} \mathrm{~s}^{-1}\right)$ despite the results from Table 4 indicating a smaller energy barrier in the last reaction. These differences are due to a much larger tunneling effect in the case of $\mathrm{R}=-\mathrm{CH}_{3}$. The rate constants for reaction (6) are slightly greater than those of reaction (5), except for $\mathrm{R}=-\mathrm{CN}$ and $-\mathrm{NO}_{2}$. It is worth mentioning that for $\mathrm{R}=$ $-\mathrm{C}(\mathrm{O}) \mathrm{OH}$ the rate constant of reaction (6) is $1.42 \times 10^{9} \mathrm{M}^{-1} \mathrm{~s}^{-1}$, almost four orders of magnitude greater than that of reaction (5), which is due in part to a larger tunneling effect in reaction (6) and to the greater stability of the pre-reactive complex too. Behind the competition between reactions (5) and (6) regarding the abstraction of the hydrogen atom linked to the $\mathrm{S}$ or $\mathrm{O}$ atoms in $\mathrm{HSOH}$, these results point clearly to the existence of a huge inductive effect of the substitute $\mathrm{R}$ in the $\mathrm{RS}^{\bullet}$ radical, which ranges up to eight order of magnitude. Table 5 also shows that the computed rate constants for reactions (4) are much smaller, between two and nine orders of magnitude than those of 


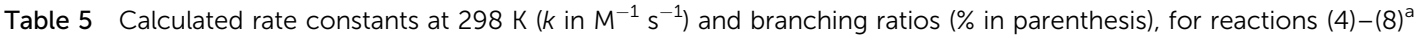

\begin{tabular}{|c|c|c|c|c|c|c|}
\hline $\mathrm{R}$ & $-\mathrm{H}^{b}(\%)$ & $-\mathrm{CH}_{3}(\%)$ & $-\mathrm{NH}_{2}(\%)$ & $-\mathrm{C}(\mathrm{O}) \mathrm{OH}(\%)$ & -CN (\%) & $-\mathrm{NO}_{2}(\%)$ \\
\hline $\begin{array}{l}\mathrm{RSOH}+\mathrm{HS}^{\bullet} \\
\text { Reaction (7) } \\
\text { Reaction (8) }\end{array}$ & $\begin{array}{c}\rightarrow \text { Products } \\
\text { b } \\
\text { b }\end{array}$ & $\begin{array}{l}3.41 \times 10^{6}(2) \\
1.74 \times 10^{8}(98)\end{array}$ & $\begin{array}{l}48.5(0) \\
2.51 \times 10^{7}(100)\end{array}$ & $\begin{array}{l}0.12(0) \\
1.19 \times 10^{7}(100)\end{array}$ & $\begin{array}{l}72.1(0) \\
1.60 \times 10^{7}(100)\end{array}$ & $\begin{array}{l}0.79(0) \\
1.32 \times 10^{9}(100)\end{array}$ \\
\hline
\end{tabular}

reactions (5) and (6), and consequently it does not play any role. Interestingly our results also show that for $\mathrm{R}=-\mathrm{H},-\mathrm{CH}_{3},-\mathrm{NH}_{2}$, and $-\mathrm{C}(\mathrm{O}) \mathrm{OH}$ reaction (6) is the majority, with branching ratios between 73 and $99 \%$, while for $\mathrm{R}=-\mathrm{CN}$, and $-\mathrm{NO}_{2}$, reaction (5) takes place between 91 and $96 \%$.

The rate constants for reaction (8) range between $1.32 \times$ $10^{9} \mathrm{M}^{-1} \mathrm{~s}^{-1}$ for $\mathrm{R}=-\mathrm{NO}_{2}$ and $6.56 \times 10^{6} \mathrm{M}^{-1} \mathrm{~s}^{-1}$ for $\mathrm{R}=-\mathrm{H}$. It is remarkable that a small value of the rate constant is computed for $\mathrm{R}=-\mathrm{NO}_{2}$, despite having a larger energy barrier, which is due to an important tunneling effect, and again our results point out the enormous importance of the inductive effects of the $\mathrm{R}$ substitute on the hydrogen transfer ability of these species. The rate constants for reaction (7) range between two and nine orders of magnitude smaller, so that the reverse reaction (3) (reaction (7)) does not play a role.

\section{Conclusions}

The reactivity of $\mathrm{RSSH}_{\text {toward }}{ }^{\bullet} \mathrm{OH}$ has not been systematically investigated either experimentally or theoretically. In this study, we have performed a high-level theoretical investigation aiming to provide mechanistic and kinetic information on the reactions between these species. Our results clearly show that two major reaction channels compete: the ${ }^{\bullet} \mathrm{OH}$ can either attack the disulfide bond or abstract the hydrogen atom of the RSSH. Additionally, an unexpected proton-coupled electron transfer mechanism (pcet) can also occur for RSSH consisting of EDGs.

The interaction of the ${ }^{\bullet} \mathrm{OH}$ with the sulfur atom induces $\mathrm{S}-\mathrm{S}$ bond cleavage and preferentially follows a backside attack mechanism. Depending on the electron inductive nature of the R substituent, a selective attack on one of the sulfur atoms is produced. For EDGs $\left(\mathrm{R}=-\mathrm{CH}_{3}\right.$ and $\left.-\mathrm{NH}_{2}\right)$, the reactions lead to a dominant formation of $\mathrm{RSOH}$ and $\mathrm{HS}^{\bullet}$ (reaction (2)), whereas for EWGs $\left(\mathrm{R}=-\mathrm{C}(\mathrm{O}) \mathrm{OH},-\mathrm{CN}\right.$ and $\left.-\mathrm{NH}_{2}\right), \mathrm{HSOH}$ and $\mathrm{RS}^{\bullet}$ (reaction (1)) are produced preferentially. Moreover, our calculations show that disulfide bond cleavage happens about two orders of magnitude faster for RSSH consisting of the EDGs than EWGs. Considering this specific reaction channel, the most reactive compound is $\mathrm{CH}_{3} \mathrm{SSH}$, having a rate constant of $3.41 \times 10^{12} \mathrm{M}^{-1} \mathrm{~s}^{-1}$ (reaction (2)), while the least reactive compound is $\mathrm{HO}(\mathrm{O}) \mathrm{CSSH}$ (reaction (1), rate constant $=1.60 \times$ $\left.10^{9} \mathrm{M}^{-1} \mathrm{~s}^{-1}\right)$.
The abstraction of the hydrogen atom by the ${ }^{\bullet} \mathrm{OH}$ (reaction (3)) leads to the formation of $\mathrm{RSS}^{\bullet}$ and $\mathrm{H}_{2} \mathrm{O}$. This is an overall fast reaction channel but the nature of the substitutes also plays an important role in affecting the reaction mechanism and kinetics. The presence of an EDG greatly speeds up this reaction channel. The computed rate constants range from $1.08 \times 10^{12} \mathrm{M}^{-1} \mathrm{~s}^{-1}\left(\mathrm{R}=-\mathrm{CH}_{3}\right)$ to $4.89 \times 10^{10} \mathrm{M}^{-1} \mathrm{~s}^{-1}$ $\left(\mathrm{R}=-\mathrm{NO}_{2}\right)$. These results point out the high ability of RSSH as $\mathrm{H}$-transfer reagents, in good agreement with the results reported recently by Chauvin and co-workers. ${ }^{21}$

One of the most interesting findings is that a pcet mechanism also occurs for RSSH having an EDG (e.g. $\mathrm{R}=-\mathrm{CH}_{3}$ ). This new reactivity is attributed to the electronic structure of the sulfur atom and it shows a huge contrast with RSSH's valance electronic isomer, $\mathrm{HOOH}$, for which the pcet does not occur. For R being the $\mathrm{H}$ atom or an $\mathrm{EWG},{ }^{\bullet} \mathrm{OH}$ abstracts the hydrogen atom (reaction (3)) through the usual hydrogen atom transfer mechanism (hat) exclusively.

Considering the competition between disulfide bond cleavage vs. H-atom transfer, RSSH consisting of the EWGs react with ${ }^{\bullet} \mathrm{OH}$ primarily through $\mathrm{H}$-atom abstraction (reaction (3)) with computed branching ratios in the range of 91-99\%. For R being a hydrogen atom or an EDG, the S-S cleavage channel can be competitive or even dominant, with branching ratios ranging from $16 \%$ $(\mathrm{R}=-\mathrm{H}), 76 \%\left(\mathrm{R}=-\mathrm{CH}_{3}\right)$, to $84 \%\left(\mathrm{R}=-\mathrm{NH}_{2}\right)$. Combining the two major reaction channels, the overall rate constants of RSSH at $298 \mathrm{~K}$ range from $4.55 \times 10^{12} \mathrm{M}^{-1} \mathrm{~S}^{-1}\left(\mathrm{R}=-\mathrm{CH}_{3}\right)$ to $5.16 \times$ $10^{10} \mathrm{M}^{-1} \mathrm{~s}^{-1}\left(\mathrm{R}=-\mathrm{NO}_{2}\right)$.

Other than the major reaction channels, the relevant sequential reactions have been investigated and new reactivity information has been acquired. For instance, the $-\mathrm{SH}$ group is a better $\mathrm{H}$-transfer reagent than the $-\mathrm{OH}$ group. That is, the rate constants involving the $\mathrm{H}$ transfer from the $-\mathrm{SH}$ group $\left(\mathrm{HSOH}+\mathrm{RS}^{\bullet} \rightarrow \mathrm{HOS}^{\bullet}+\right.$ HSR), reaction (6) are one to four-orders of magnitudes larger than the $\mathrm{H}$ transfer of the $-\mathrm{OH}$ group ( $\mathrm{HSOH}+{ }^{\bullet} \mathrm{SR} \rightarrow \mathrm{HSO}^{\bullet}+\mathrm{HSR}$ ), reaction (5). Here the tunneling effect plays an important role.

For reaction $(8)\left(\mathrm{RSOH}+\mathrm{HS}^{\bullet} \rightarrow \mathrm{RSO}^{\bullet}+\mathrm{SH}_{2}\right)$, the EDGs produce a stabilization effect on the corresponding transition states, while a significant destabilization for the EWGs. However, the fastest reaction corresponds to $\mathrm{R}=-\mathrm{NO}_{2}$, because of an important differential tunneling effect. The inductive effect of $\mathrm{R}$ leads to a difference of two orders of magnitude in the corresponding rate constants of these reactions. 
Our data clearly suggest the reaction chemistry of RSSH is rich and complex, the extent of which is closely modulated by the electronic property of the substituent group (R). Specifically, the disulfide bond cleavage channel has been historically overlooked or considered as a minor reaction pathway. However, our results demonstrate that this channel can be competitive (for $\mathrm{HSSH}$ ) or even significant (e.g., for $\mathrm{CH}_{3} \mathrm{SSH}$ ). The finding on the substantial pcet channel between $\mathrm{CH}_{3} \mathrm{SSH}$ and ${ }^{\bullet} \mathrm{OH}$ is another exciting example of the rich chemistry of RSSH, which has not been explored before. Moreover, the inductive effect of the substituents investigated in this study provides guidelines on the rational design of RSSH with the desired reactivity toward - OH attack. Our study shows that the inclusion of an EDG greatly enhances the reactivity of $\mathrm{RSSH}$. Although $\mathrm{CH}_{3} \mathrm{SSH}$ has been found as the most potent anti-oxidant in this study (overall rate constant $=4.55 \times 10^{12} \mathrm{M}^{-1} \mathrm{~s}^{-1}$ ), we envision that even more reactive RSSH species could be designed to serve as powerful radical scavengers. Our results correspond to the calculations in the gas phase and the effect of the environment, which is necessary for biological systems, will be the focus of a further investigation.

\section{Conflicts of interest}

There are no conflicts to declare.

\section{Acknowledgements}

JMA and RC thank the Spanish Secretaria de Estado de Investigación, Desarrollo e Innovación (CTQ2014-59768-P) and the Generalitat de Catalunya (Grant 2014SGR139) for financial support. They also acknowledge the Consorci de Serveis Universitaris de Catalunya (CSUC) for providing computational resources. Y. X. and S. A. acknowledge the financial support from NSF CHE-1308114 and NIH R01GM118484.

\section{References}

1 I. Braakman, J. Helenius and A. Helenius, EMBO J., 1992, 11, 1717-1722.

2 J. Janatova, K. B. M. Reid and A. C. Willis, Biochemistry, 1989, 28, 4754-4761.

3 L. Liu, C. Zhao, H. H. Q. Heng and T. Ganz, Genomics, 1997, 43, 316-320.

4 A. N. Parbhu, W. G. Bryson and R. Lal, Biochemistry, 1999, 38, 11755-11761.

5 S. Antoniow and D. Witt, Synthesis, 2007, 363-366, DOI: 10.1055/s-2007-965873.

6 R. W. Layer, Rubber Chem. Technol., 1992, 65, 211-222.

7 S. Meinardi, I. J. Simpson, N. J. Blake, D. R. Blake and F. S. Rowland, Geophys. Res. Lett., 2003, 30, 1454.

8 E. H. Krenske, W. A. Pryor and K. N. Houk, J. Org. Chem., 2009, 74, 5356-5360.

9 M. Swart, M. Sola and F. M. Bickelhaupt, J. Comput. Chem., 2007, 28, 1551-1560.
10 M. A. Van Bochove, M. Swart and F. M. Bickelhaupt, J. Am. Chem. Soc., 2006, 128, 10738-10744.

11 S. M. Bachrach and A. Pereverzev, Org. Biomol. Chem., 2005, 3, 2095-2101.

12 R. D. Bach, O. Dmitrenko and C. Thorpe, J. Org. Chem., 2008, 73, 12-21.

13 T. Ida, T. Sawa, H. Ihara, Y. Tsuchiya, Y. Watanabe, Y. Kumagai, M. Suematsu, H. Motohashi, S. Fujii, T. Matsunaga, M. Yamamoto, K. Ono, N. O. Devarie-Baez, M. Xian, J. M. Fukuto and T. Akaike, Proc. Natl. Acad. Sci. U. S. A., 2014, 111, 7606-7611.

14 É. Dóka, I. Pader, A. Bíró, K. Johansson, Q. Cheng, K. Ballagó, J. R. Prigge, D. Pastor-Flores, T. P. Dick, E. E. Schmidt, E. S. J. Arnér and P. Nagy, Sci. Adv., 2016, 2.

15 S. Longen, F. Richter, Y. Köhler, I. Wittig, K.-F. Beck and J. Pfeilschifter, Sci. Rep., 2016, 6, 29808.

16 S. S. Saund, V. Sosa, S. Henriquez, Q. N. N. Nguyen, C. L. Bianco, S. Soeda, R. Millikin, C. White, H. Le, K. Ono, D. J. Tantillo, Y. Kumagai, T. Akaike, J. Lin and J. M. Fukuto, Arch. Biochem. Biophys., 2015, 588, 15-24.

17 R. Millikin, C. L. Bianco, C. White, S. S. Saund, S. Henriquez, V. Sosa, T. Akaike, Y. Kumagai, S. Soeda, J. P. Toscano, J. Lin and J. M. Fukuto, Free Radical Biol. Med., 2016, 97, 136-147.

18 K. Ono, T. Akaike, T. Sawa, Y. Kumagai, D. A. Wink, D. J. Tantillo, A. J. Hobbs, P. Nagy, M. Xian, J. Lin and J. M. Fukuto, Free Radicals Biol. Med., 2014, 77, 82-94.

19 S. A. Everett and P. Wardman, Methods Enzymol., 1995, 251, 55-69.

20 C. L. Bianco, T. A. Chavez, V. Sosa, S. S. Saund, Q. N. N. Nguyen, D. J. Tantillo, A. S. Ichimura, J. P. Toscano and J. M. Fukuto, Free Radical Biol. Med., 2016, 101, 20-31.

21 J.-P. R. Chauvin, M. Griesser and D. A. Pratt, J. Am. Chem. Soc., 2017, 139, 6484-6493.

22 K. C. Kregel and H. J. Zhang, Am. J. Physiol.: Regul., Integr. Comp. Physiol., 2007, 292, R18-R36.

23 W. A. Pryor, K. N. Houk, C. S. Foote, J. M. Fukuto, L. J. Ignarro, G. L. Squadrito and K. J. Davies, Am. J. Physiol.: Regul., Integr. Comp. Physiol., 2006, 291, R491-R511.

24 J. M. Anglada, M. Martins-Costa, J. S. Francisco and M. F. Ruiz-Lopez, Acc. Chem. Res., 2015, 48, 575-583.

25 L. B. Poole, P. A. Karplus and A. Claiborne, Annu. Rev. Pharmacol. Toxicol., 2004, 44, 325-347.

26 R. Amorati, P. T. Lynett, L. Valgimigli and D. A. Pratt, Chem. - Eur. J., 2012, 18, 6370-6379.

27 V. Vaidya, K. U. Ingold and D. A. Pratt, Angew. Chem., Int. Ed., 2009, 48, 157-160.

28 A. J. McGrath, G. E. Garrett, L. Valgimigli and D. A. Pratt, J. Am. Chem. Soc., 2010, 132, 16759-16761.

29 A. D. Becke, J. Chem. Phys., 1993, 98, 1372-1377.

30 M. J. Frisch, J. A. Pople and J. S. Binkley, J. Chem. Phys., 1984, 80, 3265-3269.

31 W. J. Hehre, L. Radom, P. V. R. Schleyer and J. A. Pople, Ab Initio Molecular Orbital Theory, John Wiley, New York, 1986, pp. 86-87.

32 K. Ishida, K. Morokuma and A. Kormornicki, J. Chem. Phys., 1977, 66, 2153-2156. 
33 C. Gonzalez and H. B. Schlegel, J. Chem. Phys., 1989, 90, 2154-2161.

34 C. Gonzalez and H. B. Schlegel, J. Phys. Chem., 1990, 94, 5523-5530.

35 J. A. Pople, R. Krishnan, H. B. Schlegel and J. S. Binkley, Int. J. Quantum Chem., 1978, XIV, 545-560.

36 J. Cizek, Adv. Chem. Phys., 1969, 14, 35-89.

37 R. J. Barlett, J. Phys. Chem., 1989, 93, 1963.

38 K. Raghavachari, G. W. Trucks, J. A. Pople and M. HeadGordon, Chem. Phys. Lett., 1989, 157, 479.

39 T. H. J. Dunning, J. Chem. Phys., 1989, 90, 1007.

40 R. A. Kendall, T. H. Dunning and R. J. Harrison, J. Chem. Phys., 1992, 96, 6796-6806.

41 K. L. Schuchardt, B. T. Didier, T. Elsethagen, L. Sun, V. Gurumoorthi, J. Chase, J. Li and T. L. Windus, J. Chem. Inf. Model., 2007, 47, 1045-1052.

42 J. A. Pople, M. Head-Gordon and K. Raghavachari, J. Chem. Phys., 1987, 87, 5968-5975.

43 M. J. Frisch, G. W. Trucks, H. B. Schlegel, G. E. Scuseria, M. A. Robb, J. R. Cheeseman, J. J. A. Montgomery, T. Vreven, K. N. Kudin, J. C. Burant, J. M. Millam, S. S. Iyengar, J. Tomasi, V. Barone, B. Mennucci, M. Cossi, G. Scalmani, N. Rega, G. A. Petersson, H. Nakatsuji, M. Hada, M. Ehara, K. Toyota, R. Fukuda, J. Hasegawa, M. Ishida, T. Nakajima, Y. Honda, O. Kitao, H. Nakai, M. Klene, X. Li, J. E. Knox, H. P. Hratchian, J. B. Cross, C. Adamo, J. Jaramillo, R. Gomperts, R. E. Stratmann, O. Yazyev, A. J. Austin, R. Cammi, C. Pomelli, J. W. Ocherski, P. Y. Ayala, K. Morokuma, G. A. Voth, P. Salvador, J. J. Dannenberg, V. G. Zakrzewski, S. Dapprich, A. D. Daniels, M. C. Strain, O. Farkas, D. K. Malick, A. D. Rabuck, K. Raghavachari, J. B. Foresman, J. V. Ortiz, Q. Cui, A. G. Baboul, S. Clifford, J. Cioslowski, B. B. Stefanov, G. Liu, A. Liashenko, P. Piskorz, I. Komaromi, R. L. Martin, D. J. Fox, T. Keith, M. A. Al-Laham, C. Y. Peng, A. Nanayakkara, M. Challacombe, P. M. W. Gill, B. Johnson, W. Chen, M. W. Wong, C. Gonzalez and J. A. Pople, Gaussian 03, Revision C.01, Gaussian, Inc., Wallingford CT, 2004.
44 R. F. W. Bader, Atoms in Molecules. A Quantum theory, Clarendon Press, Oxford, 1995.

45 R. F. W. Bader, AIMPAC, http:/www.chemistry.mcmaster.ca/ aimpac: downloaded May 2002.

46 A. E. Reed, L. A. Curtiss and F. Weinhold, Chem. Rev., 1988, 88, 899-926.

47 G. Shaftenaar and J. H. Noordik, J. Comput.-Aided Mol. Des., 2000, 14, 123-134.

48 B. C. Garrett and D. G. Truhlar, J. Phys. Chem., 1979, 83, 1052-1078.

49 D. G. Truhlar and B. C. Garrett, Acc. Chem. Res., 1980, 13, 440-448.

50 Y. P. Liu, G. C. Lynch, T. N. Truong, D. H. Lu, D. G. Truhlar and B. C. Garrett, J. Am. Chem. Soc., 1993, 115, 2408-2415.

51 D. H. Lu, T. N. Truong, V. S. Melissas, G. C. Lynch, Y.-P. Liu, B. C. Garrett, R. Steckler, A. D. Isaacson, S. N. Rai, G. C. Hancock, J. G. Lauderdale, T. Joseph and D. G. Truhlar, Comput. Phys. Commun., 1992, 71, 235-262.

52 S. Olivella, J. M. Anglada, A. Sole and J. M. Bofill, Chem. Eur. J., 2004, 10, 3404-3410.

53 J. M. Anglada, J. Am. Chem. Soc., 2004, 126, 9809-9820.

54 J. M. Anglada and J. Gonzalez, ChemPhysChem, 2009, 10, 3034-3045.

55 J. M. Anglada, S. Olivella and A. Sole, J. Phys. Chem. A, 2006, 110, 1982-1990.

56 J. Gonzalez and J. M. Anglada, J. Phys. Chem. A, 2010, 114, 9151-9162.

57 J. M. Anglada, S. Olivella and A. Solé, J. Am. Chem. Soc., 2014, 136, 6834-6837.

58 S. Jorgensen, C. Jensen, H. G. Kjaergaard and J. M. Anglada, Phys. Chem. Chem. Phys., 2013, 15, 5140-5150.

59 R. J. Buszek, M. Torrent-Sucarrat, J. M. Anglada and J. S. Francisco, J. Phys. Chem. A, 2012, 116, 5821-5829.

60 J. M. Anglada, R. Crehuet, M. Martins-Costa, J. S. Francisco and M. Ruiz-Lopez, Phys. Chem. Chem. Phys., 2017, 19, 12331-12342.

61 J. M. Anglada, R. Crehuet and J. S. Francisco, Chem. - Eur. J., 2016, 22, 18092. 